\title{
Evolution of electron transfer out of the cell: comparative genomics of six Geobacter genomes
}

\author{
Jessica E Butler*, Nelson D Young, Derek R Lovley
}

\begin{abstract}
Background: Geobacter species grow by transferring electrons out of the cell - either to Fe(III)-oxides or to manmade substances like energy-harvesting electrodes. Study of Geobacter sulfurreducens has shown that TCA cycle enzymes, inner-membrane respiratory enzymes, and periplasmic and outer-membrane cytochromes are required. Here we present comparative analysis of six Geobacter genomes, including species from the clade that predominates in the subsurface. Conservation of proteins across the genomes was determined to better understand the evolution of Geobacter species and to create a metabolic model applicable to subsurface environments.

Results: The results showed that enzymes for acetate transport and oxidation, and for proton transport across the inner membrane were well conserved. An NADH dehydrogenase, the ATP synthase, and several TCA cycle enzymes were among the best conserved in the genomes. However, most of the cytochromes required for Fe(III)-reduction were not, including many of the outer-membrane cytochromes. While conservation of cytochromes was poor, an abundance and diversity of cytochromes were found in every genome, with duplications apparent in several species.

Conclusions: These results indicate there is a common pathway for acetate oxidation and energy generation across the family and in the last common ancestor. They also suggest that while cytochromes are important for extracellular electron transport, the path of electrons across the periplasm and outer membrane is variable. This combination of abundant cytochromes with weak sequence conservation suggests they may not be specific terminal reductases, but rather may be important in their heme-bearing capacity, as sinks for electrons between the inner-membrane electron transport chain and the extracellular acceptor.
\end{abstract}

\section{Background}

Species of the Geobacter clade specialize in the oxidation of organic compounds to carbon dioxide coupled to the reduction of insoluble, extracellular electron acceptors [1]. These species play an important role in pristine sediments and soils where they oxidize fermentation by-products like acetate and reduce naturally occurring insoluble $\mathrm{Fe}(\mathrm{III})$ and $\mathrm{Mn}$ (IV) oxides [1]. In addition, they play important roles in three biotechnical applications: they are able to degrade hydrocarbon contaminants in soils, they are able to insolubilize uranium in contaminated aquifers, and finally, they are able to transfer electrons from a variety of substrates onto graphite electrodes, from which electricity can be harvested [2-4].

\footnotetext{
* Correspondence: jbutler@microbio.umass.edu

Department of Microbiology, University of Massachusetts, Amherst, MA, USA
}

The mechanisms of electron transfer to $\mathrm{Fe}(\mathrm{III})$ and extracellular electron acceptors generally are not well understood [1]. While soluble electron acceptors like oxygen and nitrate can diffuse into the cell, Geobacter species must transfer electrons onto an essentially insoluble, and therefore extracellular, electron acceptor. Geobacter sulfurreducens is currently the model organism for the Geobacteraceae family; the genome is sequenced [5] and there is a genetic system [6]. G. sulfurreducens completely oxidizes the electron donor acetate to carbon dioxide via TCA cycle reactions [7]. Electrons are then transferred into the inner membrane, presumably via NADH dehydrogenase(s) [8], and a succinate dehydrogenase [9]. Electron transfer out of the inner membrane, through the periplasm and outer membrane to $\mathrm{Fe}(\mathrm{III})$ presumably requires $c$-type cytochromes. Several cytochromes have been shown to be required for growth by
() Biomed Central

() 2010 Butler et al; licensee BioMed Central Ltd. This is an Open Access article distributed under the terms of the Creative Commons Attribution License (http://creativecommons.org/licenses/by/2.0), which permits unrestricted use, distribution, and reproduction in any medium, provided the original work is properly cited. 
Fe(III) reduction, both in G. sulfurreducens [10-16] and in the other well-studied dissimilatory Fe(III) reducer, Shewanella oneidensis $[17,18]$. However, a specific electron transport chain to extracellular Fe(III) has not been determined for any organism.

The genomes of several closely related Fe(III)-reducing organisms in the Geobacter family have recently been sequenced. This work compares the complete or $10 \times-$ coverage draft genome sequences of six species: G. sulfurreducens, Geobacter metallireducens, Geobacter uraniireducens, Geobacter bemidjiensis, Geobacter strain FRC-32 and Geobacter lovleyi. The six Geobacter genomes were compared and conservation of electron transport proteins was determined in order to identify electron transport genes that may be critical for the reduction of $\mathrm{Fe}$ (III) and other terminal electron acceptors, to better understand the evolution of the family, and to help provide foundational data for modeling of subsurface bioremediation.

\section{Results and Discussion}

Identification of the protein families in the six Geobacter genomes

The general features of each of the six genomes are presented in Table 1. Orthologous proteins, those proteins predicted to have similar functions in the different species, were identified by Markov clustering of sets of reciprocal best BLAST matches [19]. Using all 22,434 protein coding genes in the six genomes (see Additional file 1), 4,062 protein families with at least two orthologs were defined (see Additional file 2). The families contained $17,620(79 \%)$ of all proteins. 4815 proteins were found in only one genome, and 2,196 of these were considered to be from lateral gene transfer (see Additional file 1) (discussed below). A functional role was associated with each family using the G. sulfurreducens in silico model annotation [20] and COG categorization [21].

For each protein family, its phyletic pattern - the pattern of which species encode the proteins in that family - was determined (see Additional files 2 and 3). By far the most common pattern was conservation across all species, $35 \%$ of the proteins $(7,774)$ were in families that included at least one ortholog from each genome (see Additional file 3). The second most common pattern was conservation in all of the species except G. lovleyi $6 \%(1,246)$ of the proteins had this phyletic pattern (see Additional file 3).

Forty-three protein families had at least 10 members (see Additional file 2). Thirteen of these large families were putative transposases which can be expected to be present in many copies in a genome. Other large protein families included three cytochrome families (protein family IDs 23, 31, and 45), a nickel-dependent hydrogenase family (ID 41), and two histidine kinase sensor/regulator families (IDs 7, 39) (Table 2).

\section{Phylogenetics}

A phylogeny of the family was constructed using the 697 protein families that had a single ortholog in each of the six genomes and the outgroup species Pelobacter propionicus (see Additional file 4). These proteins from each genome were concatenated then aligned, and this alignment was used to create a Bayseian model of the phylogeny (Figure 1). These proteins included many in addition to the housekeeping genes classically used to determine phylogeny, including proteins involved in information storage, metabolism, cell signaling, and those with no known function (see Additional file 4). The resulting phylogeny supports $16 \mathrm{~S}$ rDNA phylogeny [22], and shows that the subsurface species from the contaminated bioremediation sites, G. uraniireducens, $G$. strain FRC-32, and G. bemidjiensis form a group distinct from the model organisms (Figure 1). Analysis of the clustering of proteins into families showed that relatively few protein families (89, made up of 283 proteins) were found only in the three subsurface species, including a hydrogenase discussed below (see Additional file 5).

\section{Conservation of acetate and hydrogen metabolism}

In all Geobacter species, acetate is the primary electron donor and it is oxidized via the TCA cycle, generating $\mathrm{NADH}, \mathrm{NADPH}$, and reduced ferredoxin (Figure 2) $[7,23,24]$.

Table 1 Characteristics of genomes used in the comparative analysis

\begin{tabular}{|c|c|c|c|c|c|c|}
\hline & $\begin{array}{c}\text { Geobacter } \\
\text { bemidjiensis }\end{array}$ & $\begin{array}{c}\text { Geobacter sp. FRC- } \\
32\end{array}$ & $\begin{array}{c}\text { Geobacter } \\
\text { lovleyi }\end{array}$ & $\begin{array}{c}\text { Geobacter } \\
\text { metallireducens }\end{array}$ & $\begin{array}{c}\text { Geobacter } \\
\text { sulfurreducens }\end{array}$ & $\begin{array}{c}\text { Geobacter } \\
\text { uraniireducens }\end{array}$ \\
\hline NCBI ID & NC_011146 & NZ_AASH00000000 & NC_010814 & NC_007517 & NC_002939 & NC_009483 \\
\hline Contigs & 1 & 164 & 1 & 1 & 1 & 1 \\
\hline Length (nt) & $4,615,150$ & $3,982,463$ & $3,917,761$ & $3,997,420$ & $3,814,139$ & $5,136,364$ \\
\hline GC Content (\%) & 60 & 53 & 54 & 59 & 60 & 54 \\
\hline Protein coding & 4018 & 3434 & 3606 & 3519 & 3446 & 4357 \\
\hline rRNA operons & 4 & 1 & 2 & 2 & 2 & 2 \\
\hline Plasmids & none & $\mathrm{n} / \mathrm{a}$ & $77 \mathrm{~kb}$ & $13.8 \mathrm{~kb}$ & none & none \\
\hline
\end{tabular}


Table 2 The largest families of orthologous proteins (at least 10 members) excluding transposases

\begin{tabular}{|c|c|c|c|}
\hline ID & total members & Phyletic pattern & Function \\
\hline 6 & 16 & GsGmGuGfGbGl & ATP-dependent protease La \\
\hline 8 & 16 & GsGmGuGfGbGl & elongation factor $G$ \\
\hline 9 & 16 & GsGmGuGfGbGl & acetyl-CoA hydrolase/transferase \\
\hline 7 & 15 & GsGmGuGfGbGl & sensory box histidine kinase \\
\hline 11 & 14 & GsGmGuGfGbGl & CzcA family heavy metal efflux protein \\
\hline 14 & 14 & GsGmGuGfGbGl & glycosyl transferase, group 1 \\
\hline 15 & 14 & GsGmGuGfGbGl & sodium/solute symporter family protein \\
\hline 16 & 13 & Gs-GuGf-Gl & group II intron, maturase \\
\hline 17 & 12 & $-\mathrm{GmGu}-$ & hypothetical protein \\
\hline 18 & 12 & $-\mathrm{Gm}-\mathrm{Gf}-\mathrm{Gl}$ & Fis family transcriptional regulator \\
\hline 19 & 12 & GsGmGuGfGbGl & iron-sulfur cluster-binding protein \\
\hline 20 & 12 & GsGmGuGfGbGl & electron transfer flavoprotein, alpha subunit \\
\hline 21 & 12 & GsGmGuGfGbGl & molybdenum cofactor biosynthesis protein $\mathrm{A}$ \\
\hline 22 & 12 & GsGmGuGfGbGl & 1-deoxy-D-xylulose-5-phosphate synthase \\
\hline 23 & 12 & GsGmGuGfGb- & cytochrome c family protein \\
\hline 24 & 12 & GsGmGuGfGbGl & Hybrid cluster protein \\
\hline 25 & 12 & GsGmGuGfGbGl & potassium transporter family protein \\
\hline 30 & 11 & GsGmGuGfGbGl & cold-shock domain-contain protein \\
\hline 31 & 11 & GsGmGuGfGb- & high-molecular-weight cytochrome c \\
\hline 32 & 11 & GsGmGuGfGbGl & elongation factor $\mathrm{Tu}$ \\
\hline 27 & 10 & $-\mathrm{Gu}-$ & hypothetical protein \\
\hline 33 & 10 & —GuGfGb- & ATPase-like \\
\hline 36 & 10 & GsGmGuGfGb- & methyl-accepting chemotaxis protein \\
\hline 38 & 10 & GsGmGuGfGbGl & glycogen phosphorylase \\
\hline 39 & 10 & GsGmGuGfGbGl & sensor histidine kinase/response regulator \\
\hline 40 & 10 & GsGmGuGfGbGl & DNA-binding response regulator \\
\hline 41 & 10 & GsGmGu-GbGl & nickel-dependent hydrogenase, large subunit \\
\hline 42 & 10 & GsGmGuGfGbGl & malic enzyme \\
\hline 43 & 10 & GsGmGuGfGbGl & hypothetical protein GSU3410 \\
\hline 45 & 10 & GsGmGuGfGbGl & cytochrome c family protein \\
\hline
\end{tabular}

Acetate transporters were conserved in all the Geobacter species. There were two families of acetate transporters [25] that were conserved in all six species; one family contained a single ortholog from each species (GSU0518 in family 1057), and the second had multiple

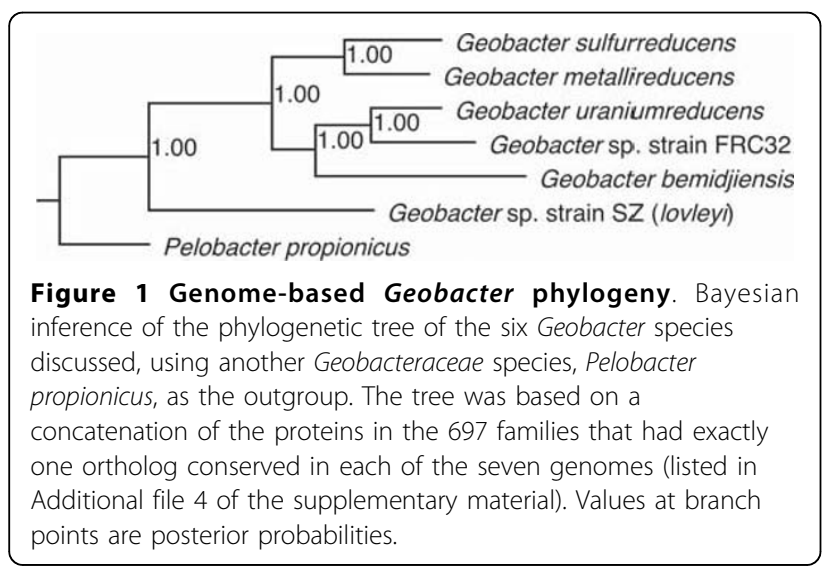

orthologs in each species (GSU1068, GSU1070, GSU2352 in 15) (see Additional file 6).

The genes for the eight reactions for acetate oxidation via the TCA cycle were conserved in all species (Figure 2). All of the subunits for acetyl-CoA transferase, citrate synthase, aconitase, isocitrate dehydrogenase, keto/oxoacid ferredoxin oxidoreductase, succinate dehydrogenase (complex II), fumarase, and malate dehydrogenase were conserved in all six of the species (see Additional file 6).

G. sulfurreducens, G. bemidjiensis, G. strain FRC-32, and $G$. lovleyi can also use hydrogen as an electron donor in addition to acetate. In G. sulfurreducens the enzyme required for hydrogen oxidation has been identified as a four-subunit NiFe hydrogenase (GSU0782GSU0785) [26]. This uptake hydrogenase was not conserved in all six of the Geobacter species; orthologs to the four subunits of this enzyme were found in three of the species that oxidize hydrogen: G. sulfurreducens, $G$. bemidjiensis, and G. lovleyi, and in one that does not: $G$. uraniireducens (see Additional file 6). No orthologs to 

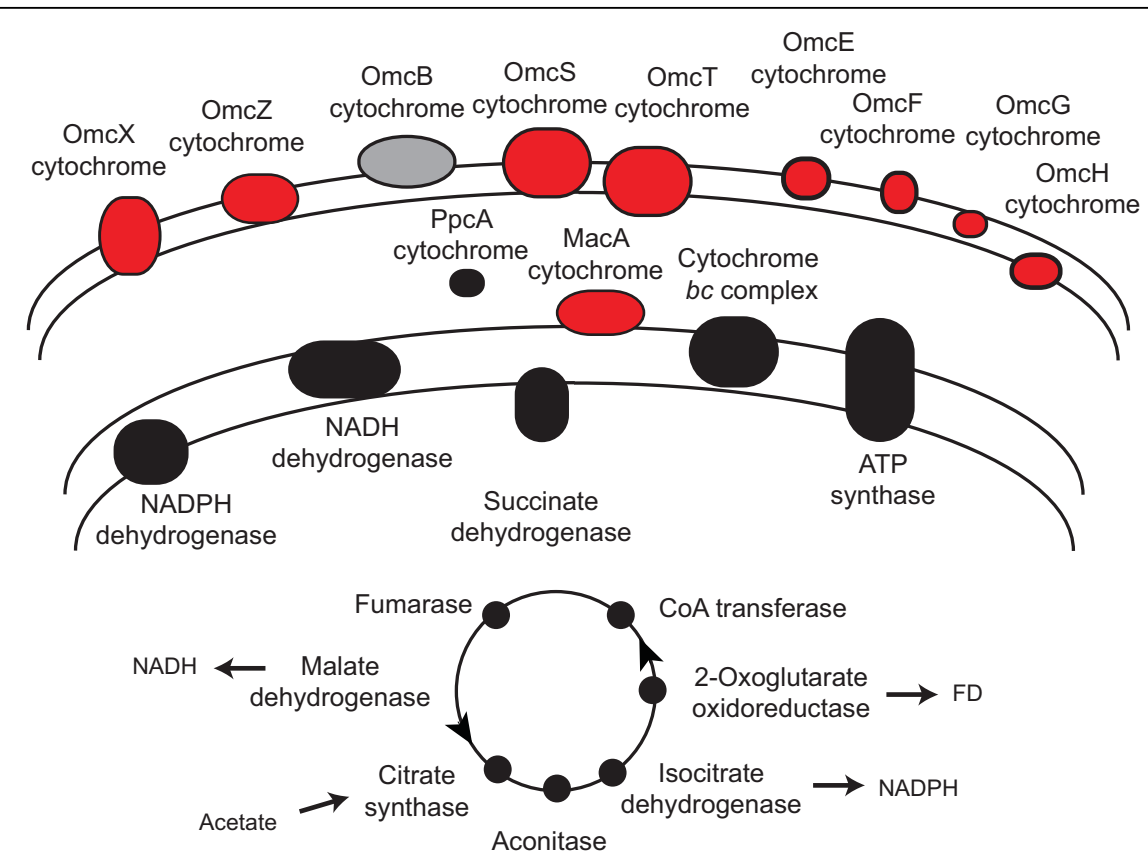

enzyme conserved in all six genomes

enzyme not conserved in all six genomes

Figure 2 Conservation of the energy metabolism pathways of Geobacter sulfurreducens. Shown are the pathways for acetate activation and oxidation via the TCA cycle in the cytoplasm; inner membrane oxidation of TCA cycle products coupled with electron/proton transport and ATP generation; and periplasmic and outer membrane cytochromes known to be required in vivo for transfer of electrons to an extracellular acceptor. The genes encoding the enzymes of these pathways and their full conservation pattern across all of the Geobacter genomes are listed in Additional file 6 of the supplementary material. The enzymes are colored black if there were orthologs for every subunit in all of the species and red if there were not. OmcB is shown in gray because there positional but not sequence-based orthologs (see text and figure 5).

this hydrogenase were found in G. strain FRC, which can oxidize hydrogen (see Additional file 6). However, G. strain FRC-32 and the other species isolated from the subsurface all encoded an additional hydrogenase, a four-subunit hydrogenase found only in these species (families 177, 178, 3032, and 3033, see Additional file 5). The four genes were similar to the heterotetrameric hydrogenase found in Pyrococcus that is a cytoplasmic, NADP-using hydrogenase [27] (Figure 3).

After acetate or hydrogen oxidation, the electrons are transferred into an inner-membrane bound electron transport chain, and protons are pumped out of the cytoplasm for ATP synthesis via an ATP synthase (Figure 2). G. sulfurreducens encodes two NADH dehydrogenases (complex I), one with 12 subunits and one with 14. This reaction is predicted to be the only one at which protons are pumped during $\mathrm{Fe}(\mathrm{III})$ or fumarate respiration [20]. All six Geobacter species contained orthologs to one of these enzymes, the 14-subunit enzyme (GSU0338-GSU0351) (see Additional file 6). The 12-subunit enzyme was conserved in all species except G. loveyi (see Additional file 6). The putative NADPH dehydrogenase [28] was conserved in all six Geobacter species (Figure 2, Additional file 6).
Regardless of whether acetate or hydrogen is the electron donor, ATP is synthesized with an inner-membrane bound ATP synthase. G. sulfurreducens encoded one ATP synthase enzyme in two gene clusters (GSU0108GSU0114 and GSU0333-GSU0334). All six Geobacter species contained orthologs to all subunits of this enzyme (Figure 2, Additional file 6).

\section{The best conserved proteins in the Geobacter species}

The level of sequence similarity among conserved proteins was estimated using bit score ratios between reciprocal orthologs [29]. 1266 G. sulfurreducens proteins had reciprocal orthologs in every other Geobacter genome (see Additional file 7). The average bit score ratio of these proteins was $70 \%$. Only a small subset, 61 proteins, had an average bit score ratio of at least $90 \%$ (Table 3). This subset of very well conserved proteins contained housekeeping proteins, including ribosomal proteins, translation elongation factors, Rho transcription termination factor, and amino acid biosynthetic genes (Table 3). This set also included proteins involved in electron transfer, including subunits of the NADH dehydrogenase and the ATP synthase from the inner membrane, and the citrate synthase and acetyl-CoA transferase from the TCA cycle (Table 3). Other high- 


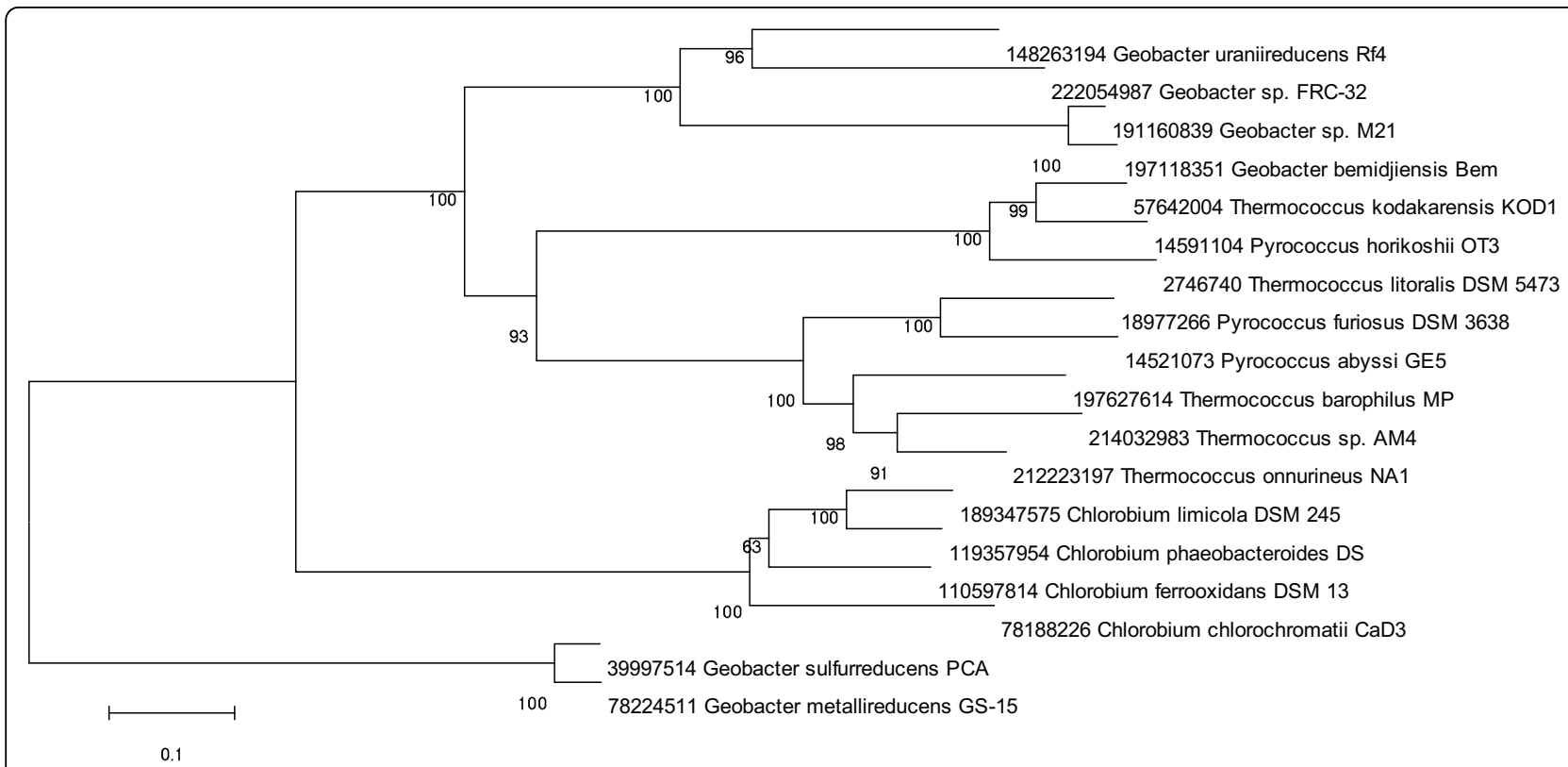

Figure 3 Neighbor-joining phylogeny of the large subunit of the four-subunit hydrogenase. This enzyme is specific to the Geobacter species of the subsurface clade, there are no orthologs in other Geobacter species. NCBI identification numbers of homologs and bootstrap values from 1000 replicates are shown.

scoring proteins (at least 85\%) included subunits of many of the other TCA cycle enzymes: succinate dehydrogenase, aconitase, malate dehydrogenase, 2-oxoglutarate oxidoreductase (see Additional file 7).

\section{Identifying genes encoding cytochromes}

After the electron donors have been oxidized and the electrons have been transferred into the inner membrane, they must then be transferred out of the cell to the extracellular electron acceptor like Fe(III) or electrodes. This pathway presumably requires periplasmic and outer-membrane $c$-type cytochromes, an abundance of which is the hallmark of Geobacter species [30,32-34]. Several cytochromes have been shown to be required for optimal growth by $\mathrm{Fe}(\mathrm{III})$ reduction or on electrodes in G. sulfurreducens: PpcA[12], MacA[13], OmcB[11], OmcE[16], OmcF[15], OmcG[35], OmcH[35], OmcS [16], OmcT[16], OmcX (M. Izallalan, unpublished), and OmcZ (B.C. Kim, unpublished).

Searching all six Geobacter species genomes showed that at least 100 ORFs in each genome contained at least one occurrence of the motif for covalent heme binding $(\mathrm{CXXCH})$, indicating that these may be cytochromes (see Additional file 8). This was more than was found in 16 other genomes including those of Shewanella, Desulfovibrio, Rhodoferax, and Anaeromyxobacter species known to be cytochrome rich (see Additional file 8). Since this definition of cytochrome is minimal, a more stringent definition was created using 26 sequence profiles described in the protein database Interpro as $c$ type cytochromes. These profiles were compared against all of the proteins in the six Geobacter genomes. Proteins were considered cytochromes if their sequence contained at least one profile match and at least one $\mathrm{CXXCH}$ motif (see Additional file 9).

These results showed that each Geobacter genome contained an average of 79 cytochromes (Table 4). G. uraniireducens contained the most cytochromes, 104, and G. lovleyi the least, 61 . On average, $2.1 \%$ of the proteins encoded in the genome of each of the Geobacter species are cytochromes (Table 4). Not only is the number of cytochromes in the genomes large, $85 \%$ of the cytochromes contain more than one heme motif - with 7.7 hemes per cytochrome on average (Table 4).

\section{Conservation of cytochromes}

While an abundance of cytochromes are found in all of the Geobacter species, very few were conserved in all six species, in contrast to the excellent conservation seen for the other energy metabolism proteins discussed above. There were 471 cytochromes in total identified in the six Geobacter genomes (see Additional file 9). Only 64 of the cytochromes (14\%) were part of a protein family that included at least one cytochrome from each of the six genomes. These 64 conserved cytochromes formed nine protein families (Table 5).

There was poor conservation across the species of many of the cytochromes that have been shown to be 
Table 3 Proteins with orthologs in every genome and average bit score ratio $\geq 90 \%$

\begin{tabular}{|c|c|c|c|}
\hline NCBI ID & Geobacter sulfurreducens gene & average score & Product Name \\
\hline 39995224 & GSU0113 & 0.97 & ATP synthase subunit B \\
\hline 39996849 & GSU1750 & 0.96 & translation initiation factor IF-1 \\
\hline 39998183 & GSU3093 & 0.96 & ribosomal protein $\mathrm{S} 21$ \\
\hline 39997962 & GSU2871 & 0.96 & translation elongation factor $\mathrm{Tu}$ \\
\hline 39996935 & GSU1836 & 0.95 & nitrogen regulatory protein P-\| \\
\hline 39996567 & GSU1467 & 0.95 & iron-sulfur cluster-binding protein \\
\hline 39998198 & GSU3108 & 0.94 & transcription termination factor Rho \\
\hline 39996934 & GSU1835 & 0.94 & glutamine synthetase \\
\hline 39997943 & GSU2851 & 0.94 & ribosomal protein $\mathrm{S3}$ \\
\hline 39996069 & GSU0966 & 0.94 & hypothetical protein GSU0966 \\
\hline 39996042 & GSU0939 & 0.94 & nitrogen regulatory protein \\
\hline 39997970 & GSU2879 & 0.94 & 3-isopropylmalate dehydrogenase \\
\hline 39995222 & GSU0111 & 0.94 & ATP synthase subunit A \\
\hline 39998429 & GSU3340 & 0.94 & 60 kDa chaperonin \\
\hline 39998543 & GSU3454 & 0.93 & radical SAM domain protein \\
\hline 39995273 & GSU0162 & 0.93 & aspartate aminotransferase \\
\hline 39996704 & GSU1604 & 0.93 & acyl carrier protein \\
\hline 39995448 & GSU0339 & 0.93 & $\mathrm{NADH}$ dehydrogenase I, B subunit \\
\hline 39996890 & GSU1791 & 0.93 & ATP-dependent protease \\
\hline 39995447 & GSU0338 & 0.93 & NADH dehydrogenase I, A subunit \\
\hline 39998155 & GSU3064 & 0.93 & cell division protein FtsA \\
\hline 39997187 & GSU2089 & 0.93 & rod shape-determining protein MreB \\
\hline 39997925 & GSU2833 & 0.93 & $30 \mathrm{~S}$ ribosomal protein S11 \\
\hline 39997939 & GSU2847 & 0.92 & ribosomal protein L14 \\
\hline 39995936 & GSU0830 & 0.92 & heavy metal efflux pump \\
\hline 39995264 & GSU0153 & 0.92 & argininosuccinate synthase \\
\hline 39997961 & GSU2870 & 0.92 & ribosomal protein L33 \\
\hline 39995685 & GSU0578 & 0.92 & glycyl-tRNA synthetase \\
\hline 39998185 & GSU3095 & 0.92 & imidazoleglycerol phosphate synthase \\
\hline 39997958 & GSU2867 & 0.92 & ribosomal protein L11 \\
\hline 39995210 & GSU0099 & 0.92 & MglA protein \\
\hline 39995598 & GSU0490 & 0.92 & acetyl-CoA hydrolase/transferase \\
\hline 39997634 & GSU2539 & 0.92 & saccharopine dehydrogenase \\
\hline 39997914 & GSU2821 & 0.91 & nitrogenase iron protein \\
\hline 39998542 & GSU3453 & 0.91 & uroporphyrinogen decarboxylase \\
\hline 39997117 & GSU2019 & 0.91 & acetyl-CoA carboxylase \\
\hline 39997929 & GSU2837 & 0.91 & preprotein translocase SecY \\
\hline 39995209 & GSU0098 & 0.91 & MglB protein \\
\hline 39995271 & GSU0160 & 0.91 & dihydrodipicolinate reductase \\
\hline 39995450 & GSU0341 & 0.91 & $\mathrm{NADH}$ dehydrogenase I, D subunit \\
\hline 39995452 & GSU0343 & 0.91 & NADH dehydrogenase I, F subunit \\
\hline 39998388 & GSU3299 & 0.91 & carboxyl transferase domain protein \\
\hline 39996631 & GSU1531 & 0.90 & phosphoribosyl-AMP cyclohydrolase \\
\hline 39996591 & GSU1491 & 0.90 & type IV pilus biogenesis protein PilB \\
\hline 39997632 & GSU2537 & 0.90 & arginine decarboxylase \\
\hline 39996434 & GSU1332 & 0.90 & heavy metal efflux pump \\
\hline 39998197 & GSU3107 & 0.90 & ribosomal protein L31 \\
\hline 39997384 & GSU2286 & 0.90 & enolase \\
\hline 39996898 & GSU1799 & 0.90 & aspartate kinase \\
\hline 39997946 & GSU2854 & 0.90 & $50 S$ ribosomal protein $L 2$ \\
\hline 39995201 & GSU0090 & 0.90 & heterodisulfide reductase subunit \\
\hline
\end{tabular}


Table 3: Proteins with orthologs in every genome and average bit score ratio $\geq \mathbf{9 0 \%}$ (Continued)

\begin{tabular}{llll}
\hline 39998045 & GSU2954 & 0.90 & arsenical-resistance protein \\
39996208 & GSU1106 & 0.90 & 0.90 \\
39996368 & GSU1266 & citrate synthase & GTP-binding protein LepA \\
39995246 & GSU0135 & 0.90 & delta-aminolevulinic acid dehydratase \\
39998096 & GSU3005 & 0.90 & thiamine biosynthesis protein ThiC \\
39997945 & GSU2853 & 0.90 & ribosomal protein S19 \\
39995451 & GSU0342 & 0.90 & NADH dehydrogenase I, E subunit \\
39997952 & GSU2860 & 0.90 & translation elongation factor G \\
39997010 & GSU1912 & 0.90 & dihydroxy-acid dehydratase \\
39998398 & GSU3309 & 0.90 & hypothetical protein GSU3309
\end{tabular}

required in vivo in G. sulfurreducens for wild-type levels of Fe(III) or electrode reduction (Figure 2). Most of the cytochromes required in G. sulfurreducens for growth on extracellular acceptors were not conserved in all species, including $\mathrm{OmcE}, \mathrm{OmcF}, \mathrm{OmcS}, \mathrm{OmcT}, \mathrm{OmcX}$, OmcZ, and MacA (Figure 2, Additional file 9).

Only one of the nine well-conserved cytochrome families contained a cytochrome, PpcA, known to be required for wild type levels of Fe(III) reduction [12]. At least one homolog to PpcA was found in every genome, and there were multiple homologs in most of the genomes: five in G. sulfurreducens, five in G. metallireducens, four in G. uraniireducens, three in G. bemidjiensis, two in G. strain FRC-32, and one in G. lovleyi (see Additional file 2 ). In related sulfate- and sulfur-reducing $\delta$-Proteobacteria species, the most abundant and best studied cytochromes are the of the tetra-heme $c_{3}$ type [36,37], while those of PpcA family are of the tri-heme $c_{7}$ type [38].

Analysis of the well-conserved cytochromes showed that four of the nine families conserved in all species were encoded together in a single cluster in each genome (Figure 4, Table 5). These conserved cytochromes were predicted to be 2-heme (GSU2930), 10-heme (GSU2934), 12-heme (GSU2935), and 5-heme (GSU 2937) (see Additional file 9). Also in this cluster were an inner-membrane-bound $b$-type cytochrome (GSU2932) and Rieske Fe-S protein (GSU2933) (Figure 4), which were clearly homologous to the core of the cytochrome $b c$ complexes $[39,40]$. The $b$-type cytochrome and the Rieske protein were also conserved in all of the genomes (see Additional file 2). In other species, the cytochrome $b c$ complex (complex III) catalyzes a key step in electron transport, that which provides the electrical link between the inner membrane and periplasm. However, the protein that provides this link in the Geobacteraceae has not been characterized, making this well-conserved cluster a good candidate for further analysis. This enzyme is especially important because it may be a second possible location of proton pumping in the cell, which would affect ATP yield during respiration, and may be different depending on the electron acceptor or on the redox potential of the cell. Typically, there is a single $c$-type cytochrome associated with this enzyme, which is a tetra-heme cytochrome in other $\delta$-Proteobacteria [41], so the role of the multiple $c$-type cytochromes in this highly-conserved cluster is novel and warrants further investigation.

There were three other cytochrome families that were well conserved in all six genomes: families of 3-heme, 9heme, and 12-heme cytochromes (Table 5). None of these cytochromes have been studied.

\section{Duplications of cytochrome genes}

Twenty-eight of the 115 families that included cytochromes had more than one protein member per

Table 4 Characteristics of cytochromes found in each genome

\begin{tabular}{|c|c|c|c|c|c|c|}
\hline & $\begin{array}{l}\text { ORFs in } \\
\text { genome }\end{array}$ & $\begin{array}{l}\text { cytochromes } \\
\text { total }\end{array}$ & $\begin{array}{l}\text { cytochromes } \\
\text { (\% genome) }\end{array}$ & $\begin{array}{c}\text { cytochromes with }>1 \\
\text { heme }\end{array}$ & $\begin{array}{c}\text { cytochromes } \\
\text { (\% } \\
\text { multiheme) }\end{array}$ & $\begin{array}{c}\text { hemes per cytochrome } \\
\text { (average) }\end{array}$ \\
\hline G. bemidjiensis & 4018 & 73 & 1.8 & 65 & 89.0 & 7.6 \\
\hline G. Iovleyi & 3685 & 61 & 1.7 & 46 & 75.4 & 4.8 \\
\hline $\begin{array}{l}\text { G. } \\
\text { metallireducens }\end{array}$ & 3532 & 76 & 2.2 & 66 & 86.8 & 7.3 \\
\hline G. strain FRC-32 & 3396 & 68 & 2.0 & 58 & 85.3 & 9.6 \\
\hline G. sulfurreducens & 3446 & 89 & 2.6 & 78 & 87.6 & 7.5 \\
\hline G. uraniireducens & 4357 & 104 & 2.4 & 91 & 87.5 & 9.3 \\
\hline average & 3739 & 79 & 2.1 & 67 & 85.3 & 7.7 \\
\hline
\end{tabular}


Table 5 Characteristics of cytochrome families with members in every genome

\begin{tabular}{ccccc}
\hline ID & members & Geobacter sulfurreducens gene & CXXCH motifs & description \\
\hline 45 & 10 & GSU1761 & 3 & ppcA and ppcB \\
49 & 9 & GSU0364 & 3 & orf2 OmcBC operon \\
51 & 9 & GSU2732 & 8 & bc complex \\
71 & 8 & GSU2937 & 5 & bc complex \\
266 & 6 & GSU2935 & 12 & bc complex \\
267 & 6 & GSU2934 & 10 & bc complex \\
271 & 6 & GSU2930 & 2 & inner membrane \\
1292 & 6 & GSU0592 & 12 & 9 \\
1467 & 6 & GSU0274 & & \\
\hline
\end{tabular}

genome (see Additional file 9). In other words, they included paralogs, which may represent duplicated cytochrome genes. The largest cytochrome family had 12 members from 5 genomes (family 23, Additional file 9). Several families were made up of cytochromes from only a single genome, indicating recent duplication or triplication of the cytochrome since that species diverged (families 3111, 3250, 3413, and 3597).

Several cytochromes known to be required for wild type Fe(III) metabolism appeared to have been duplicated within single genomes. The OmcS family (64) had nine members, all 6-heme cytochromes, found in four of the Geobacter genomes (see Additional file 9). The G. bemidjiensis genome contained four OmcS proteins, $G$. sulfurreducens three, and one in both G. FRC-32 and G. uraniireducens (see Additional file 9). The OmcZ family (2307) contained four members from three genomes: $G$. sulfurreducens had two members (see Additional file 9). All six of the Geobacter genomes contained more than one PpcA-like protein (Table 5).

The Orf2 cytochromes (GSU2732 and GSU2738) were conserved across all of the Geobacter species (Table 5), and also showed duplication. There are nine members

Geobacter sulfurreducens
Geobacter metallireducens
Geobacter sp. FRC-32
Geobacter lovleyi
Geobacter uraniumreducens
Geobacter bemidjiensis
Figure 4 The gene cluster (GSU2937 through GSU2930)
encoding the putative inner-membrane cytochrome bc
complex that is conserved in all six Geobacter species. Genes
encoding c-type cytochromes are shown in yellow, the Fe-S cluster
protein encoding gene is shown in purple, and the cytochrome $b$
gene is shown in green. All of these protein are orthologs across all
of the Geobacter genomes (Table 5). The c-type cytochromes
contain 2, 10, 12, and 5 heme-binding motifs each, respectively (see
Additional file 9).

in this family (51), all 8-heme or 9-heme cytochromes (see Additional file 9). G. sulfurreducens, G. metallireducens, and G. uraniireducens each contain two Orf2 cytochromes. In G. sulfurreducens, the Orf2 genes are encoded in a tandem repeat with another duplicated cytochrome (called $\mathrm{OmcB} / \mathrm{OmcC}$ ) known to be important for $\mathrm{Fe}(\mathrm{III})$ reduction[11] (Figure 5). Initial examination of the OmcB/OmcC family (number 1653) indicated it did not have complete conservation like the Orf2 family did, but analysis of these genes in genome context indicates that an operon of similar structure was conserved in all six species (Figure 5). Alignment of the orf2-omcB genome regions from all six species showed that there was at least one operon with similarity to the orf2-omcB operon in each genome, and furthermore, there were tandem repeats of this operon in several of the genomes (Figure 5). Interestingly, while the Orf2 cytochrome gene and the Orf1 gene immediately upstream were well conserved orthologs across all species, the gene immediately downstream varied. In all cases there was a multi-heme cytochrome encoded in the $\mathrm{OmcB} / \mathrm{C}$ spot in the operon, but the sequence similarity to $\mathrm{OmcB} / \mathrm{C}$ varied (Figure 5 ). This indicates that this operon may be important in all six species, though while it appears that conservation of the sequence of the Orf2 cytochromes is important, there may be less pressure for the larger outer membrane cytochromes to maintain a specific sequence.

\section{Lateral gene transfer}

The data presented above indicates that cytochromes are abundant in each genome, but not very well conserved across the genomes. Cytochrome duplication and divergence appears to have played a role in these genotypes. In addition, to investigate whether cytochromes were less well conserved because they were acquired laterally rather than inherited vertically, genes originating from lateral gene transfer were identified using a combination of phylogenetic and BLAST-based analysis. A neighbor-joining phylogenetic tree was inferred for every protein from the six genomes and homologous sequences for each protein were selected from the non- 


Geobacter sulfurreducens
Geobacter metallireducens
Geobacter uraniumreducens
Geobacter bemidjiensis
Geobacter lovleyi
Figure $\mathbf{5}$ The region of the operon of omcB (dark blue) in all
six Geobacter species genomes. In G. sulfurreducens the multi-
heme cytochrome OmcB, which is required for electron transport to
extracellular acceptors, is encoded in an operon with two other
genes, orf1 (red) and orf2(gray) that is duplicated in the genome
[54]. Shown here are regions of the genomes that encode the
orthologs to these genes in all six Geobacter genomes, with
orthologs colored identically. In some cases, there were multi-heme
cytochromes encoded in the position of OmcB, but the sequence
similarity was too low to confidently predict orthology, so these
genes are colored light blue.

redundant protein database. These trees were used to identify proteins for which the nearest relative was not from the Geobacteraceae. If the phylogeny was strongly supported (bootstrap $\geq 50$ ) or if the phylogeny was weakly supported and the most similar sequence in the non-redundant protein was not a Geobacteraceae species, the protein was considered a lateral gene transfer candidate.

2,196 of the 21,434 proteins in these six genomes $(9.8 \%)$ were predicted to have originated from recent transfer from a distantly related organism (see Additional file 1). Only 19 of the 472 predicted cytochromes (4.0\%) were identified as lateral gene transfer candidates - 1 in G. bemidjiensis, 5 in G. lovleyi, 6 in G. metallireducens, 2 in G. sulfurreducens, and 3 in G. uraniireducens (see Additional file 9). None of the cytochromes shown to be required for wild type electron transport in G. sulfurreducens were predicted to have originated from lateral gene transfer (see Additional file 9). These data indicated that the abundance of cytochromes in these six species cannot be explained by frequent lateral gene transfer.

\section{Conclusions}

The results show that the genes for oxidizing acetate and transferring electrons to cytoplasmic carriers, and for inner membrane electron transport, are well conserved between the Geobacter genomes. These results indicate that the Geobacter species and their last common ancestor all oxidized acetate using the same TCA cycle pathway that produces NADH, NADPH, and reduced ferredoxin. These substances are then oxidized at the inner membrane, and ATP is generated via oxidative phosphorylation. The previously unidentified site of quinol oxidation in the inner membrane is suggested to be a cytochrome $b c$ complex encoded in an unique gene cluster that is conserved in all six species. The pathways used by the better-studied species were also found to be conserved in the newly discovered species that predominate in subsurface environments undergoing bioremediation, suggesting that the current metabolic model for G. sulfurreducens [20] provides a good foundation for broader modeling of microbial metabolism in contaminated subsurfaces during bioremediation. However, the role of the newly identified hydrogenase unique to these subsurface species merits further investigation.

In stark contrast to the conservation of the pathway for ATP generation from acetate is the lack of conservation of the enzymes that dispose of the electrons after ATP production. The six Geobacter genomes contain an average of 79 cytochrome genes each, with each cytochrome predicted to bind an average of more than 7 hemes. So an abundance of extracytoplasmic heme is clearly important in these species. However, only $14 \%$ of the cytochromes are conserved in all six of the genomes. More surprisingly, even the cytochromes that have been shown to be required in G. sulfurreducens for electron transport to $\mathrm{Fe}(\mathrm{III})$ or electrodes are not well conserved.

Cells of G. sulfurreducens have been shown to be capable of storing ca. $1.6 \times 10^{-17} \mathrm{~mol}$ electrons in the iron of their cytochromes [42]. This has lead to the proposal that cytochromes may act as electric capacitors, accepting and storing the electrons from energy metabolism for short time spans in the absence of an extracellular electron-accepting surface [43]. The data presented here indicates that in these species there is a combination of strong pressure to maintain many cytochrome genes with weak pressure to maintain the sequence of most cytochrome genes. This lack of conservation of cytochrome genes suggests that in Geobacter species there may not be a single common pathway for electron transport outside the cell, and that cytochromes may be required for general Fe-bearing capacity, as sinks for electrons between the inner-membrane electron transport chain and the extracellular acceptor.

\section{Methods}

\section{Genome sequencing and annotation}

With the exception of G. sulfurreducens [5], sequence data for the genomes were produced by the US Department of Energy Joint Genome Institute http://www.jgi. doe.gov, using a whole-genome shotgun strategy for the Sanger-sequencing of $3-\mathrm{Kb}, 8-\mathrm{Kb}$, and $40-\mathrm{Kb}$ DNA libraries to $8-9 \mathrm{X}$ depth. Open reading frames and their translations and predicted function based on automated annotation were taken from NCBI http://www.ncbi.nlm. nih.gov/, and are listed in Additional file 1 of the supplementary material. The following motifs were used to 
annotate cytochromes (showing Interpro identification http://www.ebi.ac.uk/interpro/): IPR000298, IPR000763, IPR000883， IPR000883， IPR001128， IPR002016, IPR002016, IPR002321， IPR002322， IPR002585, IPR003317, IPR004203, IPR009056, IPR010176, IPR010177, IPR010255, IPR010960, IPR011031, IPR011048, IPR012282, IPR012292, SSF47175, SSF48613, SSF48695, SSF81342, SSF81648.

\section{Clustering orthologs into protein families}

All proteins in the genomes were clustered into families of orthologs and recent paralogs using OrthoMCL [19], which uses reciprocal best similarity pairs from all-vs-all BLAST [44] to identify orthologs and recent paralogs, which are then clustered together across all the genomes using the Markov clustering algorithm [45]. A functional role was predicted for each cluster using the G. sulfurreducens in silico model annotation [20] and COG categorization [21]. The level of sequence similarity among conserved proteins was estimated using bit score ratios between reciprocal orthologs [29].

\section{Phylogenetics}

All the ORFs from the six genomes and the outgroup species Pelobacter propionicus (NC_008609) were put into orthologous groups using $\mathrm{Hal}$ [46], with inflation parameters from 1.1-5.0 for the clustering algorithm. The proteins used for the phylogeny were those that were part of a cluster generated with any inflation value that had exactly one member from each genome, and are listed in Additional file 4 of the supplementary material. All of the proteins in the cluster were concatenated and the resulting sequences aligned by ClustalW [47]. ProtTest [48] was used to select a model of molecular evolution and MrBayes [49] was used to create a Bayesian estimation of the phylogeny. The single gene phylogeny was inferred from a ClustalW[47] alignment of homologs to the large subunit of the hydrogenase from the NCBI non-redundant database. Distances and branching order were determined by the neighbor-joining method[50] with bootstrap values from 1000 replicates in Mega[51].

\section{Lateral gene transfer}

A phylogenetic tree was inferred using PhyloGenie [52] for every protein from the six genomes. Homologous sequences for each protein were selected by BLAST from the non-redundant protein database from NCBI http://www.ncbi.nlm.nih.gov/, alignments were created with ClustalW [47], and the phylogeny was inferred using neighbor-joining [50] and 100 bootstrapped replicates. If, for a given protein, a phylogenetic relationship with non-Geobacteraceae was strongly-supported (bootstrap $\leq 50$ ) or if the relationship was weakly supported and the most similar sequence in the non-redundant protein database from NCBI was not a Geobacteraceae species, the protein was considered a candidate. If the next branch out contained a single sequence not from Geobacteraceae species, the query gene was defined as being from lateral transfer. If the next branch contained a single sequence from Geobacteraceae, it was not. If the sister group was a clade or was not strongly supported, the ancestral condition was inferred [53] and used to determine lateral transfer.

\footnotetext{
Additional file 1: All proteins referenced in this study. Spreadsheet with NCBI identification numbers and descriptions including name, predicted function, COG membership, protein family ID, family

conservation pattern, and lateral transfer prediction.

Click here for file

[http://www.biomedcentral.com/content/supplementary/1471-2164-1140-S1.XLS ]
}

Additional file 2: Protein families and their members from each of the genomes. Spreadsheet showing protein families of orthologs, with descriptions including ID, predicted function, member proteins, member genomes, family size, and conservation pattern.

Click here for file

[http://www.biomedcentral.com/content/supplementary/1471-2164-1140-S2.XLS ]

Additional file 3: Frequency of the phyletic patterns of protein conservation. Spreadsheet showing the number of proteins with a given pattern of conservation.

Click here for file

[http://www.biomedcentral.com/content/supplementary/1471-2164-1140-S3.XLS ]

Additional file 4: Proteins used in the whole genome phylogeny. Spreadsheet showing the IDs of the proteins used.

Click here for file

[http://www.biomedcentral.com/content/supplementary/1471-2164-1140-S4.XLS ]

Additional file 5: Proteins conserved only within the species in the subsurface clade. Spreadsheet showing the proteins that were conserved in all and only the species in the subsurface clade including ID, protein family ID, conservation of family, and predicted function. Click here for file

[http://www.biomedcentral.com/content/supplementary/1471-2164-1140-S5.XLS ]

Additional file 6: Conservation of proteins involved in the energy metabolism of anaerobic respiration Spreadsheet showing all of the proteins with their metabolic role, conservation pattern, reaction abbreviation in the constraint-based model, protein family, and genomes of family members.

Click here for file

[http://www.biomedcentral.com/content/supplementary/1471-2164-1140-S6.XLS ]

Additional file 7: Proteins conserved in all genomes (with reciprocal orthologs in every genome). Spreadsheet showing all of the proteins that had reciprocal best BLAST matches in every single other genomes with their metabolic role, reaction abbreviation in the constraint-based model, bit score ratio for the reciprocal best BLAST match in every other genome, and average bit score ratio.

Click here for file

[http://www.biomedcentral.com/content/supplementary/1471-2164-1140-S7.XLS ]

Additional file 8: Total heme motifs in $\mathbf{2 3}$ cytochrome-rich genomes. Spreadsheet showing totals of heme binding motifs $(\mathrm{CxxCH})$ in 23 completed genomes, including total genes with heme motif(s), most hemes per gene, number of genes with more than one motif and percent with more than one motif.

Click here for file

[http://www.biomedcentral.com/content/supplementary/1471-2164-1140-S8.XLS ] 
Additional file 9: Cytochromes in all Geobacter genomes

Spreadsheet showing all of the proteins predicted to encode cytochromes in all of the Geobacter genomes, with the number of heme binding motifs, protein family, conservation pattern, number of members in the family, lateral transfer prediction, published gene name, and paralog prediction

Click here for file

[http://www.biomedcentral.com/content/supplementary/1471-2164-1140-S9.XLS]

\section{Acknowledgements}

This research was supported by the Office of Science (BER), U. S. Department of Energy, Cooperative Agreement No. DE-FC02-02ER63446.

\section{Authors' contributions}

JEB carried out the conservation analysis, created the physiological models, constructed the single gene phylogenies, and drafted the manuscript. NDY designed the method for and carried out the lateral gene transfer prediction, constructed the whole genome phylogeny, and carried out the clustering method. DRL conceived of the study and helped draft the manuscript. All authors read and approved the final manuscript.

Received: 22 June 2009

Accepted: 17 January 2010 Published: 17 January 2010

\section{References}

1. Lovley DR, Holmes DE, Nevin KP: Dissimilatory Fe(III) and Mn(IV) reduction. Adv Microb Physiol 2004, 49:219-286.

2. Bond DR, Holmes DE, Tender LM, Lovley DR: Electrode-reducing microorganisms that harvest energy from marine sediments. Science 2002, 295(5554):483-485.

3. Lovley DR: Bug juice: harvesting electricity with microorganisms. Nat Rev Microbiol 2006, 4(7):497-508.

4. Tender LM, Reimers CE, Stecher HA, Holmes DE, Bond DR, Lowy DA, Pilobello K, Fertig SJ, Lovley DR: Harnessing microbially generated power on the seafloor. Nat Biotechnol 2002, 20(8):821-825.

5. Methe BA, Nelson KE, Eisen JA, Paulsen IT, Nelson W, Heidelberg JF, Wu D, Wu M, Ward N, Beanan MJ, Dodson RJ, Madupu R, Brinkac LM, Daugherty SC, DeBoy RT, Durkin AS, Gwinn M, Kolonay JF, Sullivan SA Haft DH, Selengut J, Davidsen TM, Zafar N, White O, Tran B, Romero C, Forberger HA, Weidman J, Khouri H, Feldblyum TV, Utterback TR, Van Aken SE, Lovley DR, Fraser CM: Genome of Geobacter sulfurreducens: metal reduction in subsurface environments. Science 2003, 302(5652):1967-1969.

6. Coppi MV, Leang C, Sandler SJ, Lovley DR: Development of a genetic system for Geobacter sulfurreducens. Appl Environ Microbiol 2001, 67(7):3180-3187

7. Galushko AS, Schink B: Oxidation of acetate through reactions of the citric acid cycle by Geobacter sulfurreducens in pure culture and in syntrophic coculture. Arch Microbiol 2000, 174(5):314-321.

8. Mahadevan R, Bond DR, Butler JE, Esteve-Nunez A, Coppi MV, Palsson BO, Schilling $\mathrm{CH}$, Lovley DR: Elucidating central metabolism in the Fe(III) reducing organism Geobacter sulfurreducens by constraints-based modeling. Appl Environ Microbiol 2006, 72(2):1558-1568.

9. Butler JE, Glaven RH, Esteve-Nunez A, Nunez C, Shelobolina ES, Bond DR, Lovley DR: Genetic characterization of a single bifunctional enzyme for fumarate reduction and succinate oxidation in Geobacter sulfurreducens and engineering of fumarate reduction in Geobacter metallireducens. J Bacteriol 2006, 188(2):450-455.

10. Magnuson TS, Isoyama N, Hodges-Myerson AL, Davidson G, Maroney MJ, Geesey GG, Lovley DR: Isolation, characterization and gene sequence analysis of a membrane-associated $89 \mathrm{kDa}$ Fe(III) reducing cytochrome $c$ from Geobacter sulfurreducens. Biochem J 2001, 359(Pt 1):147-152.

11. Leang C, Coppi MV, Lovley DR: OmcB, a c-type polyheme cytochrome, involved in Fe(III) reduction in Geobacter sulfurreducens. J Bacterio/ 2003, 185(7):2096-2103.

12. Lloyd JR, Leang C, Hodges Myerson AL, Coppi MV, Cuifo S, Methe B, Sandler SJ, Lovley DR: Biochemical and genetic characterization of PpcA a periplasmic c-type cytochrome in Geobacter sulfurreducens. Biochem $J$ 2003, 369(Pt 1):153-161.

13. Butler JE, Kaufmann F, Coppi MV, Nunez C, Lovley DR: MacA, a diheme ctype cytochrome involved in $\mathrm{Fe}$ (III) reduction by Geobacter sulfurreducens. J Bacteriol 2004, 186(12):4042-4045.

14. Afkar E, Reguera G, Schiffer M, Lovley DR: A novel Geobacteraceae-specific outer membrane protein $\mathrm{J}(\mathrm{OmpJ})$ is essential for electron transport to $\mathrm{Fe}(\mathrm{III})$ and $\mathrm{Mn}(\mathrm{IV})$ oxides in Geobacter sulfurreducens. BMC Microbiol 2005, 5(41).

15. Kim BC, Leang C, Ding YH, Glaven RH, Coppi MV, Lovley DR: OmcF, a putative c-Type monoheme outer membrane cytochrome required for the expression of other outer membrane cytochromes in Geobacter sulfurreducens. J Bacteriol 2005, 187(13):4505-4513.

16. Mehta T, Coppi MV, Childers SE, Lovley DR: Outer membrane c-type cytochromes required for $\mathrm{Fe}$ (III) and $\mathrm{Mn}$ (IV) oxide reduction in Geobacter sulfurreducens. Appl Environ Microbiol 2005, 71(12):8634-8641.

17. Beliaev AS, Saffarini DA, McLaughlin JL, Hunnicutt D: MtrC, an outer membrane decahaem c cytochrome required for metal reduction in Shewanella putrefaciens MR-1. Mol Microbiol 2001, 39(3):722-730.

18. Pitts KE, Dobbin PS, Reyes-Ramirez F, Thomson AJ, Richardson DJ, Seward HE: Characterization of the Shewanella oneidensis MR-1 decaheme cytochrome MtrA: expression in Escherichia coli confers the ability to reduce soluble Fe(III) chelates. J Biol Chem 2003, 278(30):2775827765.

19. Li L, Stoeckert CJ Jr, Roos DS: OrthoMCL: identification of ortholog groups for eukaryotic genomes. Genome Res 2003, 13(9):2178-2189.

20. Mahadevan R, Bond DR, Butler JE, Esteve-Nunez A, Coppi MV, Palsson BO, Schilling CH, Lovley DR: Characterization of metabolism in the Fe(III)reducing organism Geobacter sulfurreducens by constraint-based modeling. Appl Environ Microbiol 2006, 72(2):1558-1568.

21. Tatusov RL, Koonin EV, Lipman DJ: A genomic perspective on protein families. Science 1997, 278(5338):631-637.

22. Holmes DE, O'Neil RA, Vrionis HA, N'Guessan LA, Ortiz-Bernad I, Larrahondo MJ, Adams LA, Ward JA, Nicoll JS, Nevin KP, Chavan MA, Johnson JP, Long PE, Lovley DR: Subsurface clade of Geobacteraceae that predominates in a diversity of $\mathrm{Fe}($ (III)-reducing subsurface environments. ISME J 2007, 1(8):663-677.

23. Champine JE, Goodwin S: Acetate catabolism in the dissimilatory ironreducing isolate GS-15. J Bacteriol 1991, 173(8):2704-2706.

24. Paulsen J, Kroger A, Thauer RK: ATP-driven succinate oxidation in the catabolism of Desulfuromonas acetoxidans. Arch Microbiol 1986, 144:202207

25. Risso C, Methe BA, Elifantz H, Holmes DE, Lovley DR: Highly conserved genes in Geobacter species with expression patterns indicative of acetate limitation. Microbiology 2008, 154(Pt 9):2589-2599.

26. Coppi MV, O'Neil RA, Lovley DR: Identification of an uptake hydrogenase required for hydrogen-dependent reduction of $\mathrm{Fe}(\mathrm{IIII})$ and other electron acceptors by Geobacter sulfurreducens. J Bacteriol 2004, 186(10):3022-3028.

27. Vignais PM, Billoud B, Meyer J: Classification and phylogeny of hydrogenases. FEMS Microbiol Rev 2001, 25(4):455-501.

28. Coppi MV, O'Neil RA, Leang C, Kaufmann F, Methe BA, Nevin KP, Woodard TL, Liu A, Lovley DR: Involvement of Geobacter sulfurreducens SfrAB in acetate metabolism rather than intracellular, respiration-linked Fe(III)-citrate reduction. Microbiology 2007, 153(10):3572-3585.

29. Rasko DA, Myers GS, Ravel J: Visualization of comparative genomic analyses by BLAST score ratio. BMC Bioinformatics 2005, 6(1)-2.

30. Holmes DE, Nicoll JS, Bond DR, Lovley DR: Potential role of a novel psychrotolerant member of the family Geobacteraceae, Geopsychrobacter electrodiphilus gen. nov., sp. nov., in electricity production by a marine sediment fuel cell. Appl Environ Microbiol 2004, 70(10):6023-6030.

31. Caccavo F Jr, Lonergan DJ, Lovley DR, Davis M, Stolz JF, Mclnerney MJ: Geobacter sulfurreducens sp. nov., a hydrogen- and acetate-oxidizing dissimilatory metal-reducing microorganism. Appl Environ Microbiol 1994 60(10):3752-3759.

32. Lovley DR, Giovannoni SJ, White DC, Champine JE, Phillips EJ, Gorby YA, Goodwin S: Geobacter metallireducens gen. nov. sp. nov., a microorganism capable of coupling the complete oxidation of organic compounds to the reduction of iron and other metals. Arch Microbiol 1993, 159(4):336344

33. Nevin KP, Holmes DE, Woodard TL, Hinlein ES, Ostendorf DW, Lovley DR: Geobacter bemidjiensis sp. nov. and Geobacter psychrophilus sp. nov., 
two novel Fe(III)-reducing subsurface isolates. Int I Syst Evol Microbiol 2005, 55(Pt 4):1667-1674.

34. Straub KL, Buchholz-Cleven BE: Geobacter bremensis sp. nov. and Geobacter pelophilus sp. nov., two dissimilatory ferric-iron-reducing bacteria. Int I Syst Evol Microbiol 2001, 51(Pt 5):1805-1808.

35. Kim BC, Qian X, Leang C, Coppi MV, Lovley DR: Two Putative c-Type Multiheme Cytochromes Required for the Expression of OmcB, an Outer Membrane Protein Essential for Optimal Fe(III) Reduction in Geobacter sulfurreducens. J Bacteriol 2006, 188(8):3138-3142.

36. Louro RO: Proton thrusters: overview of the structural and functional features of soluble tetrahaem cytochromes c3. J Biol Inorg Chem 2007, 12(1):1-10.

37. Aragao D, Frazao C, Sieker L, Sheldrick GM, LeGall J, Carrondo MA: Structure of dimeric cytochrome $\mathrm{C} 3$ from Desulfovibrio gigas at 1.2 A resolution. Acta Crystallogr D Biol Crystallogr 2003, 59(Pt 4):644-653.

38. Pokkuluri PR, Londer YY, Duke NE, Long WC, Schiffer M: Family of cytochrome c7-type proteins from Geobacter sulfurreducens: structure of one cytochrome c7 at 1.45 A resolution. Biochemistry 2004, 43(4):849859 .

39. Berry EA, Guergova-Kuras M, Huang LS, Crofts AR: Structure and function of cytochrome bc complexes. Annu Rev Biochem 2000, 69:1005-1075.

40. Crofts AR: The cytochrome bc1 complex: function in the context of structure. Annu Rev Physiol 2004, 66:689-733.

41. Kramer DM, Nitschke W, Cooley JW: The Cytochrome bc1 and Related bc Complexes: The Rieske/Cytochrome b Complex as the Functional Core of a Central Electron/Proton Transfer Complex. The Purple Phototrophic Bacteria Beatty JT: SpringerHunter CN, Daldal F, Thurnauer MC 2009, 451473.

42. Esteve-Nunez A, Sosnik J, Visconti P, Lovley DR: Fluorescent properties of c-type cytochromes reveal their potential role as an extracytoplasmic electron sink in Geobacter sulfurreducens. Environ Microbiol 2008, 10(2):497-505.

43. Lovley DR: Extracellular electron transfer: wires, capacitors, iron lungs, and more. Geobiology 2008, 6(3):225-231.

44. Altschul SF, Madden TL, Schaffer AA, Zhang J, Zhang Z, Miller W, Lipman DJ: Gapped BLAST and PSI-BLAST: a new generation of protein database search programs. Nucleic Acids Res 1997, 25(17):3389-3402.

45. Enright AJ, Van Dongen S, Ouzounis CA: An efficient algorithm for largescale detection of protein families. Nucleic Acids Res 2002, 30(7):1575-1584.

46. Robbertse B, Reeves JB, Schoch CL, Spatafora JW: A phylogenomic analysis of the Ascomycota. Fungal Genet Biol 2006, 43(10):715-725.

47. Thompson JD, Higgins DG, Gibson TJ: CLUSTAL W: improving the sensitivity of progressive multiple sequence alignment through sequence weighting, position-specific gap penalties and weight matrix choice. Nucleic Acids Res 1994, 22(22):4673-4680

48. Abascal F, Zardoya R, Posada D: ProtTest: selection of best-fit models of protein evolution. Bioinformatics 2005, 21(9):2104-2105.

49. Ronquist F, Huelsenbeck JP: MrBayes 3: Bayesian phylogenetic inference under mixed models. Bioinformatics 2003, 19(12):1572-1574.

50. Saitou N, Nei M: The neighbor-joining method: a new method for reconstructing phylogenetic trees. Mol Biol Evol 1987, 4(4):406-425.

51. Tamura K, Dudley J, Nei M, Kumar S: MEGA4: Molecular Evolutionary Genetics Analysis (MEGA) software version 4.0. Mol Biol Evol 2007, 24(8):1596-1599.

52. Frickey T, Lupas AN: PhyloGenie: automated phylome generation and analysis. Nucleic Acids Res 2004, 32(17):5231-5238.

53. Swofford DL, Madison WP: Reconstructing ancestral character states under Wagner parsimony. Math Biosci 1987, 87:199-229.

54. Leang C, Lovley DR: Regulation of two highly similar genes, omcB and omcC, in a $10 \mathrm{~kb}$ chromosomal duplication in Geobacter sulfurreducens. Microbiology 2005, 151(Pt 6):1761-1767.

doi:10.1186/1471-2164-11-40

Cite this article as: Butler et al.: Evolution of electron transfer out of the cell: comparative genomics of six Geobacter genomes. BMC Genomics 2010 11:40. 